\title{
Ten years' experience of screening patients with Barrett's oesophagus in a university teaching hospital
}

\author{
C E Macdonald, A C Wicks, R J Playford
}

\begin{abstract}
Background-Barrett's metaplasia is a premalignant condition for which screening is recommended.

Aims/methods-Annual screening endoscopies have been performed on all subjects suitable for surgery for many years. To examine the benefits to patients of continuing this policy 10 years' experience of screening for Barrett's oesophagus was reviewed.

Results-Of the 29374 endoscopies performed over this period, Barrett's metaplasia was present in $1.4 \%$. There was an approximate equal sex distribution with the majority of cases being identified in patients over 50 years old. Thirty five per cent of these patients were suitable to enter a yearly screening programme. During screening, the length of oesophagus involved did not vary over time. As a result of 379 endoscopies performed for screening purposes, only one patient was identified as developing carcinoma solely as a result of the screening programme. Two further patients had carcinoma identified as a result of progressive dysphagia requiring additional endoscopies. All three patients who developed carcinoma while in the screening programme had "long segment" (>8 cm) regions of Barrett's metaplasia with a stricture present at the initial endoscopy.

Conclusions-The poor yield from this screening programme suggests that the policy should be reconsidered. Resources may be better spent on focusing on patients who present with ulceration or stricture in addition to Barrett's metaplasia.

(Gut 1997; 41: 303-307)
\end{abstract}

Keywords: malignancy; endoscopy; oesophageal carcinoma

The definition of Barrett's oesophagus ${ }^{1}$ is contentious and the criteria for diagnosing Barrett's metaplasia has varied over time. The definition may depend on an arbitrary minimal length of columnar epithelium lining the distal oesophagus (usually $>3 \mathrm{~cm}$ ). Alternatively, it has been defined as the presence of specialised Barrett's metaplasia on biopsy containing goblet cells which stain positively for acid mucus as opposed to the neutral mucin normally found in gastric mucosa. ${ }^{2}$ Columnar cells positive for acid mucus, resembling intestinal mucosa, are particularly common in patients with short segment Barrett's oesophagus. ${ }^{3}$ Barrett's oesophagus extending over a distance greater than $3 \mathrm{~cm}$ has been reported to occur in about 1 in 400 of the general population, ${ }^{4}$ or about $15 \%$ of patients with reflux oesophagitis. ${ }^{5}$ There is also increasing interest in the large number of asymptomatic individuals who have short segment Barrett's oesophagus $(<3 \mathrm{~cm})$ as this can also can give rise to adenocarcinoma, ${ }^{67}$ and is present in about $10 \%$ of all patients presenting for endoscopy. ${ }^{8}$

Barrett's oesophagus is a condition that is generally considered to be premalignant and therefore it has been recommended that patients identified as having Barrett's oesophagus are regularly screened to detect and treat early oesophageal cancer. ${ }^{6-12}$ Factors reported to increase the risk of malignant transformation include smoking, ${ }^{13} 14$ length of Barrett's oesophagus $>8 \mathrm{~cm},{ }^{6}{ }^{15}$ and male sex. ${ }^{9}{ }^{16}$

The natural history of Barrett's oesophagus is poorly understood although it seems likely that in a proportion of patients, the metaplastic Barrett's mucosa develops progressive dysplasia that subsequently forms adenocarcinoma. The rationale behind a screening programme is to detect patients with dysplasia or early cancer and so improve survival. The most effective management of dysplasia found on screening is controversial, as oesophagectomy has an associated mortality. The risk-benefit comparison of performing this radical procedure for a premalignant condition must therefore depend on local experience. ${ }^{17}$ To complicate matters further, the incidence of adenocarcinoma of the oesophagus in patients with Barrett's metaplasia is unclear. Estimates of frequency range from 1 in 40 to 1 in 441 patient years. ${ }^{13} 1819$

Given the uncertainties in the natural history of this condition, the benefits of entering large numbers of patients into a screening programme are uncertain. A report using Markov type decision analyses (computer modelling based on published work) suggests that screening provides benefit at an acceptable cost. ${ }^{12}$ However, this benefit has not been shown in a clinical study.

The clinical gastroenterologists in our hospital have had a policy of offering screening on an annual basis to all patients found to have Barrett's metaplasia who were deemed fit for oesophageal surgery, should this be required. In this paper we review our experience and its impact on clinical outcome. 


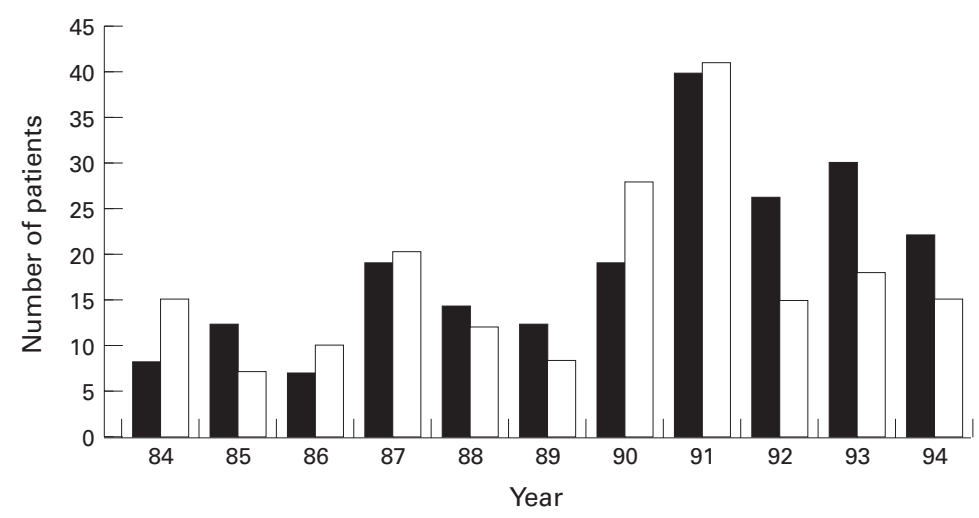

Figure 1: Number of new patients identified in our endoscopy unit as having Barrett's metaplasia present over the period 1984-1994. Black columns represent male patients and white columns female patients.

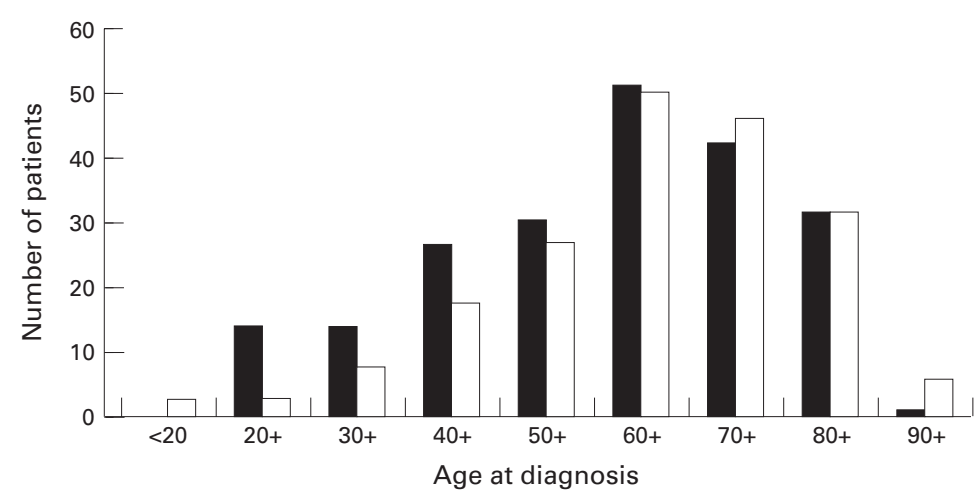

Figure 2: Age of patients at time of initial diagnosis of Barrett's metaplasia. Black columns represent male patients and white columns female patients.

\section{Methods}

The reports from all endoscopies performed during the period 1984-1994 (total number 29 374) were reviewed by a single observer (CEM). The vast majority $(89 \%)$ were performed in approximate equal numbers by three consultants (two gastroenterologists and an oesophageal surgeon). Any reports that suggested the presence of Barrett's oesophagusfor example, short oesophagus, high oesophagogastric junction, columnar oesophagus, or hiatus hernia as well as actual Barrett's oesophagus were identified and investigated in further detail.

Using records from this hospital, other local hospitals and the general practitioners these index cases were examined in more detail. This included age, sex, evidence of any previous endoscopy performed elsewhere (including participation in a screening programme) and any additional illnesses. Indications for the initial and subsequent endoscopies were taken from the referral or clinic letter, directly from the case notes or from the request form. To maintain consistency of the definition of the presence of Barrett's oesophagus over the 10 year period, patients were considered to have Barrett's oesophagus only if there was an area of biopsy confirmed columnar metaplasia extending over a region greater or equal to $3 \mathrm{~cm}$. This definition will therefore have excluded patients who are now considered to have short segment Barrett's oesophagus.
Assessment of Barrett's mucosa at endoscopy comprised length of macroscopic involved mucosa and other abnormalities such as presence of ulceration or stricture. Biopsies were typically performed in all four quadrants at the mid-point of the involved mucosa. Multiple biopsy specimens were also taken of any macroscopic abnormality (such as stricture or ulcer). Mapping was not performed. Biopsy samples were immediately fixed in $10 \%$ formalin and processed routinely. Sections were cut and stained using haematoxylin and eosin. Barrett's mucosa was reported if glandular mucosa was recognised in a biopsy specimen of oesophagus. Intestinal metaplasia (recognised on the basis of prominent goblet cells) was reported if present. As is normal practice at this hospital, biopsy samples which were thought to contain dysplasia or cancer were reviewed by two consultant histopathologists to confirm diagnosis. Areas of dysplasia were defined as showing mild, moderate or severe dependent on the degree of nuclear atypia and pseudostratification.

Endoscopies following diagnosis were defined as screening endoscopies if they were described as such and occurred solely for that reason. If a patient was entered into the screening programme and subsequently developed deteriorating symptoms (for example, haematemesis) which required an additional endoscopy, this episode was not considered as a screening examination.

The completeness of data capture was assessed by also independently reviewing the separate pathology and hospital coding records reporting the presence of Barrett's oesophagus during the year 1993. This method did identify a number of subjects $(n=40)$ who had Barrett's oesophagus recognised at necropsy or on histology of resected cancers. Importantly, none of these additional patients had been endoscoped in the screening programme.

\section{Results}

CHARACTERISTICS OF ALL PATIENTS IDENTIFIED AS HAVING BARRETT'S METAPLASIA

Of the 29374 upper gastrointestinal endoscopies performed during this 10 year period, 409 patients were recognised to have Barrett's oesophagus macroscopically for the first time. The number of new patients identified on a year to year basis showed an apparent increase from 1990 onwards (fig 1). This reflected an increase in the total number of endoscopies being performed in the hospital and the percentage of total endoscopies that showed the presence of Barrett's oesophagus remained constant at about $1.4 \%$ throughout the 10 year period. There was an approximate equal sex distribution with the majority of cases being identified in subjects over 50 years old (fig 2), the mean age being 63 years. At this diagnostic endoscopy, the average length of Barrett's mucosa was $7.6 \mathrm{~cm}$ with a stricture present in $35 / 409(8 \%)$.

MODE OF PRESENTATION

The reasons for the endoscopy leading to the initial diagnosis of Barrett's metaplasia are 


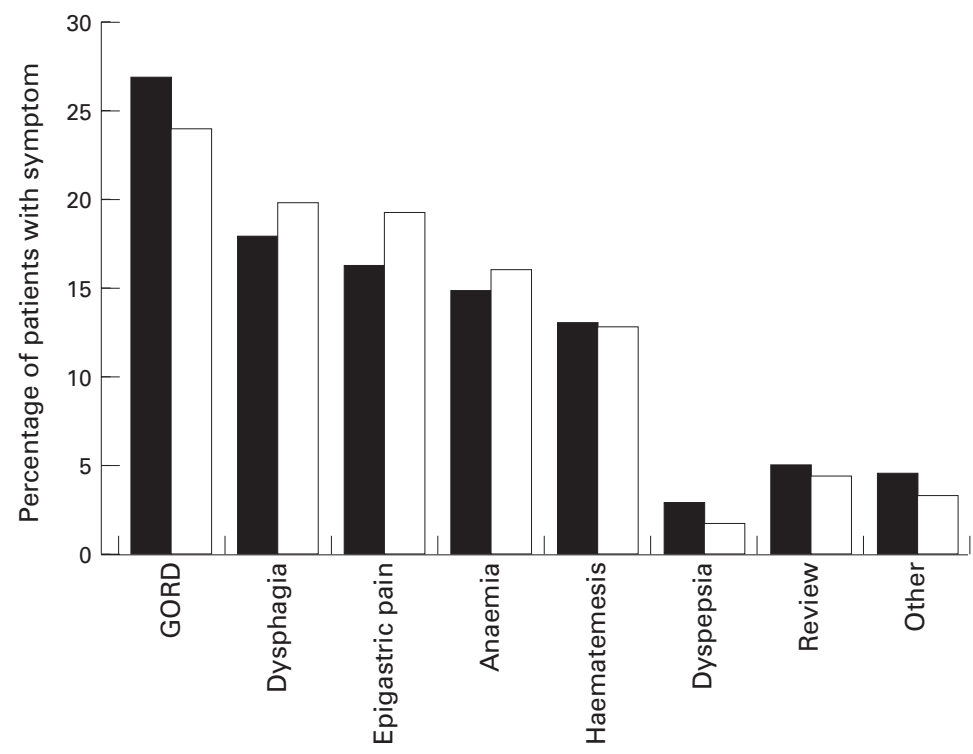

Figure 3: Symptoms or clinical indication for the initial endoscopy which led to the recognition of the presence Barrett's metaplasia. Black columns represent male patients and white columns female patients. GORD, symptoms suggestive of gastro-oesophageal reflux. Review, repeat endoscopy to confirm healing of benign gastric ulceration where Barrett's metaplasia was not commented on at the initial endoscopy.

shown in fig 3 . The main groupings were symptoms of: gastro-oesophageal reflux disease, epigastric pain (suggestive of peptic ulcer), overt gastrointestinal bleeding (haematemesis or melaena), iron deficiency anaemia (endoscopy for assessment of anaemia without any gastrointestinal symptoms), and dysphagia. Of the patients presenting with dysphagia $(n=77)$, about one third had an apparent abnormality on endoscopy that probably accounted for their symptoms. This consisted of oesophageal ulcer in 17 subjects and the presence of a stricture or web in 10 subjects. The two other identified groups consisted of patients complaining of dyspepsia (where the symptoms were not particularly suggestive of reflux or peptic ulceration) and patients who were having repeat endoscopies for benign gastric ulceration (review group).

ENTRY INTO SCREENING PROGRAMME

The entry criteria used to select patients suitable for entry into the screening programme were those aged under 70 without serious coexisting disease, such as ischaemic heart disease or chronic obstructive airways disease. Thirty five per cent (143/409) of all subjects identified as having Barrett's metaplasia were deemed suitable to enter into the programme. The predominant reasons for not entering the screening programme are shown in fig 4, the most common reason for exclusion being that the patient was over 70 years of age. All subjects entered into the screening protocol had histologically confirmed Barrett's metaplasia; this was of the intestinal form in $18 \%$ (26/ 143). All participants underwent regular assessment for the presence of dysplasia throughout the screening programme.

Patients entered into the screening programme had a slight male predominance $(60 \%)$ with an average age of 47 years. The symptoms or clinical indications precipitating

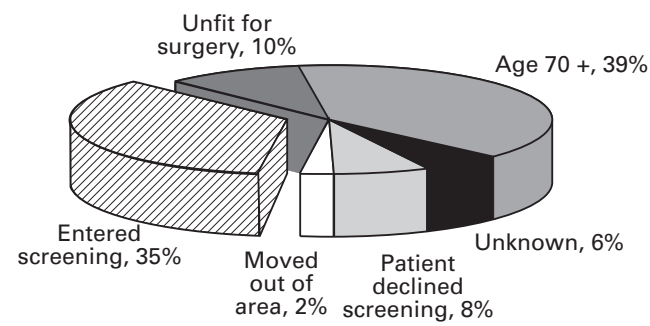

Figure 4: Pie chart showing the percentage of potentially suitable patients who entered the screening programme and the main reason for exclusion in the rest.

the diagnostic endoscopy in this subgroup comprised epigastric pain in $23 \%$, gastrooesophageal reflux disease in $21 \%$, dysphagia in $20 \%$, anaemia in $11 \%$, and haematemesis in $7 \%$ (a similar distribution to that seen in all patients identified with Barrett's metaplasia). The mean length of Barrett's metaplasia at initial endoscopy was $8.1 \mathrm{~cm}$ with a stricture also being present in $23(16 \%)$.

During the 10 years that the screening programme was running, the endoscopy unit identified a total of 466 patients with carcinoma of the oesophagus at initial endoscopy. Of these, 11 subjects had a histologically confirmed combination of Barrett's metaplasia and carcinoma. All 11 subjects had an associated stricture, 10 having a final diagnosis of adenocarcinoma and one squamous carcinoma.

RESULTS OF SCREENING PROGRAMME

Over the 10 year period, 379 screening endoscopies were performed. An additional 144 endoscopies were performed on the same patients for deteriorating or changing symptoms. This was usually for dysphagia or haematemesis. The attendance rate for the first annual screening of each patient who had been identified as suitable for entry into the programme and who had agreed to participate was $74 \%$, with no identified cause for failure to attend in the remainder. In subsequent years there was a $77 \%$ attendance rate among those still living in the area. A medical reason (death or the development of other serious pathology precluding screening) was identified in half of these non-attenders that accounted for their failure to attend.

There was no difference in the average length of Barrett's metaplasia between men and women. The average length of Barrett's metaplasia in the patients participating in the screening programme did not change with time $(8.1 \mathrm{~cm}$ at initial and $8.3 \mathrm{~cm}$ at last endoscopy).

Four patients had mild dysplasia. Three of these patients had a history of alcoholism. One was lost to follow up, the others all had normal biopsy specimens on subsequent review suggesting regression of the dysplasia.

The summary details of the three patients who developed cancer after an interval of screening are presented in the box. Importantly, only one of the patients developing cancer was identified purely because of the screening programme all the others being detected as 
Clinical details of the three patients entered into the Barrett's metaplasia screening programme who subsequently developed carcinoma

- Sixty four year old woman. Diagnostic endoscopy for dysphagia showed a benign stricture in a $10 \mathrm{~cm}$ length of Barrett's mucosa with intestinal metaplasia. She was entered into the screening programme but four months later progressive dysphagia required additional endoscopies. Multiple endoscopies over the next year were performed due to the high suspicion of malignancy. An adenocarcinoma was only confirmed at necroscopy.

- Sixty four year old woman. Diagnostic endoscopy for dysphagia showed a benign stricture in an $11 \mathrm{~cm}$ length of Barrett's mucosa with no evidence of dysplasia. She was entered into the screening programme but three months later, increasing dysphagia prompted four additional endoscopies over the next nine months. The last of these identified squamous carcinoma. She was treated surgically and is alive three years later.

- Sixty three year old man. Diagnostic endoscopy for dysphagia showed a benign stricture in a $10 \mathrm{~cm}$ length of Barrett's mucosa with no evidence of dysplasia. An endoscopy performed 10 years previously had revealed the presence of long segment non-dysplastic Barrett's mucosa. He was entered into the screening programme and the next two annual reviews showed no change with no dysplasia. On the third annual review an asymptomatic adenocarcinoma was identified. The patient was treated surgically but died one month later.

a result of changes in symptoms requiring an additional endoscopy.

\section{Discussion}

We have found that about $1.4 \%$ of all patients undergoing endoscopy have Barrett's metaplasia. This is probably a reflection of the large number of relatively asymptomatic cases in the community. ${ }^{20}$ Our finding that the prevalence of Barrett's metaplasia increases to a peak in late middle age agrees with the findings of others. ${ }^{22}{ }^{23}$ The sex distribution of Barrett's metaplasia has been reported to be equal in some studies, ${ }^{9}$ in keeping with our results, or to have a male predominance. ${ }^{1624}$ The screening programme generated an additional 379 endoscopies but identified only one patient with asymptomatic carcinoma.

The natural history of Barrett's metaplasia is poorly understood. Although it is generally accepted that there is a strong link between gastro-oesophageal reflux disease and Barrett's metaplasia, the severity of symptoms is a poor guide to the macroscopic damage. Symptomatology therefore cannot be used to select patients at high risk of developing Barrett's metaplasia. Our study found that $8 \%$ of all patients with Barrett's metaplasia had a stricture present at initial presentation. It has been suggested that patients who report symptoms of dysphagia and have Barrett's metaplasia present are at increased risk of developing cancer. ${ }^{25}$ The high prevalence of stricture, ${ }^{18}$ and the abnormal oesophageal motility associated with Barrett's metaplasia, ${ }^{26}$ probably explains the dysphagic symptoms reported by these patients.

All three of the patients in the screening programme who were subsequently confirmed to have carcinoma had a stricture present as well as long segment $(>8 \mathrm{~cm})$ Barrett's metaplasia at the initial endoscopy. This finding supports previous work suggesting that the risk of developing tumour is much higher in subjects presenting with a stricture associated with Barrett's metaplasia, ${ }^{27}{ }^{28}$ and if the length of Barrett's mucosa is $>8 \mathrm{~cm} .{ }^{9}{ }^{15}$ The presence of an ulcer in an area of Barrett's metaplasia has also been reported to be a risk factor for the subsequent development of malignant transformation. ${ }^{29}$ Two of the subjects had deteriorating symptoms before their initial annual review, and it is possible that carcinoma was actually present at the time of entry into the programme. Interestingly, one of the subjects was found to have a squamous carcinoma within the area of Barrett's metaplasia. This association has occasionally been reported previously. ${ }^{30}{ }^{31}$ The third subject did not develop carcinoma until three years into the screening programme, making it unlikely that a carcinoma was missed at the entry endoscopy.

There are a number of criteria that a screening programme must meet to be successful. ${ }^{32}$ These include that the natural history of the disease to be treated must be understood, that there is an asymptomatic stage which screening can detect that is amenable to effective treatment and that the treatment alters outcome to the patient's or community's benefit. In addition, the screening test used must be effective and acceptable to those undergoing it. Based on the results reported in this paper, we feel that our present screening strategy fails to meet these criteria.

Several other groups have examined the value of endoscopic screening for Barrett's oesophagus but no consensus has been reached as yet. Our conclusions are at variance with those reported by Wright et al who screened a similar number of subjects $(n=166)$ over the period 1981-1992. They identified six patients as developing carcinoma whilst participating in their screening programme. ${ }^{16}$ Importantly, in contrast to our findings, five of the six subjects were asymptomatic at the time of diagnosis. In contrast, a study by van der Burgh et $a l,{ }^{29}$ examined the clinical outcome of patients who had biopsy confirmed Barrett's oesophagus who were not entered into a screening programme. Eight years after diagnosis $79 / 155$ had died and of these, five had developed oesophageal cancer but in only two of these cases was this thought to have been the cause of death. They concluded that screening is unlikely to be of clinical benefit for patients with Barrett's oesophagus given its small contribution to mortality. A similar conclusion was reached in the study by Cameron et al. ${ }^{18}$ Although there is little evidence that overall mortality is reduced by entering patients with Barrett's mucosa into a screening programme, 
several studies suggest that it does lead to diagnosis of the tumour at an earlier stage at time of surgical resection. ${ }^{1133}$

The costs of performing endoscopy with histological assessment at our hospital are similar to those quoted by Wright et al ( $£ 80$ (\$127) per endoscopy with $£ 40$ (\$64) for histological assessment per endoscopy), giving a cost of about $£ 49000$ (\$78 400) to detect our one asymptomatic cancer patient. However, costbenefit analyses are virtually meaningless when dealing with such small numbers and multicentre trials would have to be undertaken to assess accurately the financial costs of detecting patients with asymptomatic carcinoma.

In summary, our screening programme resulted in the identification of only one patient with asymptomatic carcinoma but resulted in an additional workload equivalent to one month's work by our entire endoscopy unit. This leads us to question the value of continuing this programme. Resources may be better spent on focusing on subjects who present with Barrett's metaplasia affecting $>8 \mathrm{~cm}$, particularly concentrating on patients with coexisting ulceration or stricture.

We thank Dr J F Mayberry and Mr P S Veitch for their help with the screening programme and Scientific Hospital Supplies for the screening prog
funding $(\mathrm{CEM})$.

1 Barrett NR. Chronic peptic ulcer of the oesophagus and 'oesophagitis'. Br f Surg 1950; 38: 175-82.

2 Rubin CE, Haggitt RC, Levine DS. Endoscopic mucosal biopsy. In: Yamada T, ed. Textbook of gastroenterology. biopsy. In: Yamada T, ed. Textbook of gastr

3 Spechler SJ, Goyal RK. The columnar-lined esophagus, intestinal metaplasia, and Norman Barrett. Gastroenterology 1996; 110: 614-21

4 Stein HJ, Siewert JR. Barrett's esophagus: pathogenesis, epidemiology, functional abnormalities, malignant degeneration, and surgical management. Dysphagia 1993; 8: 276-88.

5 Bartlesman JF, Hameeteman W, Tytgat GN. Barrett's oesophagus. Eur f Cancer Prev 1992; 1: 323-5.

6 Clark GW, Smyrk TC, Burdiles P, Hoeft SF, Peters JH, Kiyabu M, et al. Is Barrett's metaplasia the source of adenocarcinomas of the cardia? Arch Surg 1994; 129: 60914.

7 Schnell TG, Sontag SJ, Chejfec G. Adenocarcinomas arising in tongues or short segments of Barrett's esophagus. Dig Dis Sci 1992; 37: 137-43.

8 Johnston MH, Hammond AS, Laskin W, Jones DM. The prevalance and clinical characteristics of short segments of specialised intestinal metaplasia in the distal esophagus on specialised intestinal metaplasia in the distal esophagus on

9 routine endoscopy. Am f Gastroenterol 1996; 91: 1507-11. Menke-Pluymers MB, Hop WC, Dees J, van Blankenstein
M, Tilanus HW. Risk factors for the development of an adenocarcinoma in columnar-lined (Barrett) esophagus. The Rotterdam Esophageal Tumor Study Group. Cancer 1993; 72: 1155-8.
10 Atkinson M, Iftikhar SY, James PD, Robertson CS, Steele RJ. The early diagnosis of oesophageal adenocarcinoma by

11 Streitz JM Jr, Andrews CW Jr, Ellis FH Jr. Endoscopic surveillance of Barrett's esophagus. Does it help? f Thorac Cardiovasc Surg 1993; 105: 383-7.

12 Provenzale D, Kemp JA, Arora S, Wong JB. A guide for surveillance of patients with Barrett's esophagus. Am $\mathcal{F}$ Gastroenterol 1994; 89: 670-80.

13 Spechler SJ, Robbins AH, Rubins HB, Vincent ME, Heeren $T$, Doos WG, et al. Adenocarcinoma and Barrett's esophagus. An overrated risk? Gastroenterology 1984; 87: 927-33.

14 Gray MR, Donnelly RJ, Kingsnorth AN. The role of smoking and alcohol in metaplasia and cancer risk in Barrett's columnar lined oesophagus. Gut 1993; 34: 727-31.

15 Iftikhar SY, James PD, Steele RJ, Hardcastle JD, Atkinson M. Length of Barrett's oesophagus: an important factor in the development of dysplasia and adenocarcinoma. Gut 1992; 33: 1155-8.

16 Wright TA, Gray MR, Morris AI, Gilmore IT, Ellis A, Smart HL, et al. Cost effectiveness of detecting Barrett's cancer. Gut 1996; 39: 574-9.

17 Riddell RH. Early detection of neoplasia of the esophagus and gastroesophageal junction. Am f Gastroenterol 1996; 91: 853-63.

18 Cameron AJ, Ott J, Payne WS. The incidence of adenocarcinoma in columnar lined (Barrett's) esophagus. $N$ Engl f Med 1985; 313: 857-9.

19 Van der Veen A H, Dees J, Blankenstein JD, Van Blankenstein M. Adenocarcinoma in Barrett's oesophagus: an overrated risk. Gut $1989 ; 30: 14-8$.

20 Spechler SJ, Goyal RK. Barretts Oesophagus. N Engl f Med 1986; 315: 362-72.

21 Cameron AJ, Zinsmeister AR, Ballard DJ, Carney JA. Prevalance of columnar-lined (Barrett's) esophagus. Gastroenterology, 1990; 99: 918-22.

22 Bonelli L. Barrett's esophagus: results of a multicentric survey. G.O.S.P.E. (Gruppo Operativo per lo Studio delle Precancerosi Esofagee). Endoscopy 1993; 25: 652-4

23 Cameron AJ, Lomboy CT. Barrett's esophagus: age, prevalence, and extent of columnar epithelium. Gastroenterology 1992; 103: 1241-5.

24 Loof L, Gotell P, Elfberg B. The incidence of reflux oesophagitis. A study of endoscopy reports from a defined catchment area in Sweden. Scand f Gastroenterol 1993; 28: $113-8$.

25 Chow WH, Finkie WD, McLaughlin JK, Franki H. The relationship of gastroesophageal reflux disease and its treatment to adenocarcinomas of the esophagus and gastric cardia. fAMA 1995; 274: 474-7.

26 Mason RJ, Bremner CC. Motility differences between longsegment and short-segment Barrett's esophagus. Am f Surg 1993; 165: 686-9.

27 Moghissi K, Sharpe DA, Pender D. Adenocarcinoma and Barrett's oesophagus. A clinico-pathological study. Eur $\mathcal{f}$ Cardiothorac Surg 1993; 7: 126-31.

28 Lerut T, Coosemans W, Van Raemdonck D, Dillemans B, De Leyn P, Marnette JM, et al. Surgical treatment of Barrett's carcinoma. Correlations between morphologic findings and prognosis. F Thorac Cardiovasc Surg 1994; 107: 1059-65.

29 van der Burgh A, Dees J, Hop WCJ, van Blankenstein M. Oesophageal cancer is an uncommon cause of death in patients with Barrett's oesophagus. Gut 1996; 39: 5-8.

30 Paraf F, Flejou JF, Potet F, Molas G, Fekete F. Esophageal squamous carcinoma in five patients with Barrett's esophagus. Am f Gastroenterol 1992; 87: 746-50.

$31 \mathrm{Li} \mathrm{H}$, Walsh TN, Hennessy TP. Carcinoma arising in Barrett's esophagus. Surg Gynecol Obstet 1992; 175: 167-72.

32 Wilson JMG, Junger G. Principles and practice of screening for disease. Geneva: World Health Organisation, 1968

33 Moon MR, Schulte WJ, Haasler GB, Condon RE. Transhiatal and transthoracic esophagectomy for adenocarcinoma of the esophagus. Arch Surg 1992; 127: 951-5. 